\title{
Fentanyl-induced rigidity during emergence from general anesthesia potentiated by venlafexine
}

\author{
[La rigidité induite par le fentanyl, pendant le retour à la conscience qui suit \\ l'anesthésie générale, est potentialisée par la venlafexine]
}

Sébastien Roy BPHARM MD, Louis-Philippe Fortier MSc MD FRCPC

Purpose: To present and discuss a case of opioid-induced rigidity with low-dose fentanyl during recovery from anesthesia.

Clinical features: A 4I-yr-old woman underwent laparotomy for total abdominal hysterectomy and bilateral salpingo- oophorectomy under general anesthesia. She received a total of $500 \mu \mathrm{g}$ of fentanyl by iv intermittent boluses during the three-hour anesthetic. During emergence from anesthesia, while intubated, the patient presented with rigidity. No changes in ventilatory parameters were measured during the episode. The only notable predisposing factor was treatment with venlafexine, an antidepressant that modifies serotonin and norepinephrine levels. She was successfully treated with iv naloxone $20 \mu \mathrm{g}$. The rest of the postoperative period was uneventful.

Conclusion: We observed an atypical case of opioid-induced rigidity in contrast to the classical syndrome, which presents at induction with high-dose opioids. This syndrome has many clinical presentations with neurologic and ventilatory signs of varying intensity. Early recognition of the syndrome and adequate treatment is crucial. If treated adequately, opioid-induced rigidity is self-limited with few complications.

Objectif : Faire la présentation et la discussion d'un cas de rigidité induite par un opioïde avec du fentanyl à faible dose pendant le retour à la conscience après l'anesthésie.

Éléments cliniques : Une femme de 41 ans devait subir une laparotomie pour une hystérectomie abdominale totale et une salpingo-ovariectomie bilatèrale sous anesthésie générale. Elle a reçu une dose totale de $500 \mu \mathrm{g}$ de fentanyl en bolus iv intermittents pendant les trois heures de l'anesthésie. Au réveil, encore intubée, la patiente a présenté de la rigidité. Aucun changement des paramètres ventilatoires n'ont cependant été noté pendant cet épisode. Le seul facteur prédisposant notable était le traitement à la venlafexine, un antidépresseur qui modifie les niveaux de sérotonine et de noradrénaline. Le traitement iv avec $20 \mu \mathrm{g}$ de naloxone a été un succès. Aucun autre incident postopératoire n'est survenu.
Conclusion : Nous avons observé un cas atypique de rigidité induite par un opioïde est temporaire et s'accompagne rarement de complications, cas différent du syndrome classique qui se présente à l'induction avec des doses élevées d'opioïdes. Ce syndrome présente de nombreux tableaux cliniques dont des signes neurologiques et ventilatoires d'intensité variable. Le diagnostic précoce du syndrome et le traitement adapté sont donc très importants. Traitée adéquatement, la rigidité induite par un opiö̈de se limite à quelques complications.

$\mathrm{P}$

OWERFUL synthetic opioids used in anesthesia can cause muscle rigidity. The incidence and intensity of rigidity varies greatly. Rigidity classically presents with the use of high-dose opioids during induction of anesthesia in the non-paralyzed patient. ${ }^{l}$ Rigidity also occurs during emergence from anesthesia. Although opioid-induced rigidity is part of the differential diagnosis of agitation and abnormal motor symptoms during emergence, it is rare, especially with low doses of opioids. We report and discuss an atypical case of opioid-induced rigidity during recovery from anesthesia with low doses of fentanyl.

\section{Case report}

A 41-yr-old woman was brought to the operating room for emergency laparoscopy, total abdominal hysterectomy, and bilateral salpingo-oophorectomy. Her sole medical history was depression, which was currently treated with venlafexine. Her physical examination and routine laboratory studies were normal. The patient received $i m$ meperidine $50 \mathrm{mg}$ before arrival to the operating room.

Anesthesia was induced with iv fentanyl $150 \mu \mathrm{g}$, propofol $160 \mathrm{mg}$, and rocuronium $50 \mathrm{mg}$. The tra-

From the Département d'anesthésiologie, Université de Montréal, Montréal, Québec, Canada.

Address correspondence to: Dr. Louis-Philippe Fortier, Département d'anesthésiologie, Hôpital Maisonneuve- Rosemont, 5415, boul. de

l'Assomption, Montréal, Québec HIT 2M4, Canada. Phone: 514-252-3426; Fax: 514-252-3542; E-mail: hmranest@odyssee.net

Accepted for publication March 28, 2002.

Revision accepted June 16, 2002. 
chea was easily intubated. Anesthesia was maintained with desflurane in oxygen, intermittent iv boluses of rocuronium for muscle relaxation, and $i v$ boluses of fentanyl for analgesia. Mechanical ventilation was adjusted to maintain an end- tidal $\mathrm{pCO}_{2}$ between 32 and $34 \mathrm{mmHg}$. The patient's hemodynamic and respiratory parameters remained stable during the uneventful three-hour anesthetic. The patient received a total of $2.5 \mathrm{~L}$ of lactated Ringer's solution, rocuronium $110 \mathrm{mg}$, and fentanyl $500 \mu \mathrm{g}$.

At the end of the surgery, muscle relaxation was reversed with iv neostigmine $2.5 \mathrm{mg}$ and glycopyrrolate $0.6 \mathrm{mg}$. The patient resumed spontaneous ventilation while receiving desflurane $>1$ MAC. Prior to any sign of emergence, the patient developed neck and masseter muscle spasm, jaw closure, thoraco-abdominal rigidity, upper limb flexion, and lower limb extension with plantar flexion. Neurological examination showed isocoric $2 \mathrm{~mm}$ pupils with upward gaze deviation, bilateral bicipital, patellar, and Achilles tendon hyperreflexia, and sustained ankle clonus (more apparent on the right side), but no signs of lateralization. Vital signs were normal $\left(\mathrm{SpO}_{2} 98 \%\right.$, respiratory rate 16 breaths $\mathrm{min}^{-1}$, heart rate 70 beats $\mathrm{min}^{-1}$, blood pressure $130 / 70 \mathrm{mmHg}$ ). Ventilation pressure was not significantly affected. The lungs were normal on auscultation. Her hemodynamic and respiratory parameters were stable. To rule out fentanyl-induced rigidity, we treated the patient with $i v$ naloxone $20 \mu \mathrm{g}$. The muscle spasm and neurologic signs subsided less than two minutes after the administration of naloxone. The patient was awakened and her trachea was extubated without any problems.

Postoperatively, the patient was transferred to the recovery room for further monitoring. Patient-controlled analgesia with iv morphine was started under direct monitoring for two hours without recurrence of any symptoms and the patient was sent to the ward. Six hours later, she had given herself a total of $36 \mathrm{mg}$ morphine iv and was mildly drowsy, but was coherent and oriented to person, place, and time. Her neurological examination was normal. The remainder of her postoperative course was uneventful.

\section{Discussion}

We witnessed an atypical case of opioid-induced rigidity. Atypical features include the low dose of opioid used and the presentation at emergence. The concomitant use of venlafexine, which affects norepinephrine and serotonin levels, may have been a contributing factor. The absence of ventilatory difficulties in an intubated patient supports the hypothesis that laryngeal closure may be the principal cause of the
TABLE Differential diagnosis of agitation and abnormal motor symptoms during emergence

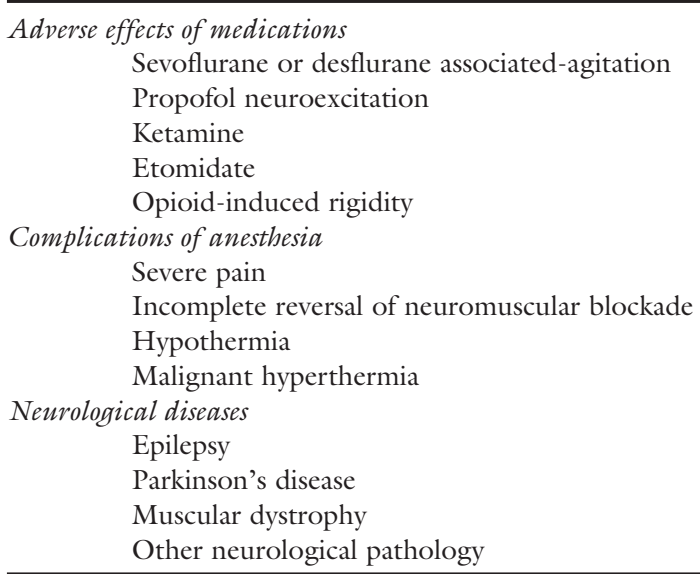

compromised ventilation typically seen in this syndrome. The reversal of symptoms upon administration of naloxone is supportive, although not definitive, of the diagnosis of opioid-induced rigidity.

\section{Differential diagnosis}

The atypical presentation of our patient led us to consider a number of other possible diagnoses of agitation and abnormal motor symptoms during emergence (Table). Our patient received a number of other drugs that could be responsible for her clinical features. Propofol has been implicated in neurological hyperstimulation during induction or emergence. ${ }^{2}$ The myotonic and dystonic movements, muscular hypertonus, opisthotonus, and seizures may appear as late as five hours after administration. ${ }^{2-5}$ Our patient did not show opisthotonus or any dystonic movements, which are two principal signs of propofol neuroexcitation. The delayed presentation, three hours after the single bolus of propofol, also makes the diagnosis of propofol neuroexcitation improbable.

Volatile anesthetics could also cause similar clinical signs. Desflurane has been associated with agitation upon emergence, significantly more so than sevoflurane, halothane, or propofol-remifentanil anesthesia. ${ }^{6,7}$ Reported cases of agitation with desflurane have shown clear signs of emergence prior to agitation. Interestingly $i v$ fentanyl $2.5 \mu \mathrm{g} \cdot \mathrm{kg}^{-1}$ may prevent desflurane-induced agitation. ${ }^{8}$ These findings were observed in the pediatric population, in which emergence agitation is more common than in adults. Neurological signs aside from agitation, similar to 
those manifested by our patient, have been observed with enflurane and, to a lesser degree, isoflurane, ${ }^{9}$ but has never been described with desflurane, despite the similarity of the compounds. In our case, desflurane was unlikely to be the causative agent as the patient still had significant end-tidal levels of desflurane and was unconscious when symptoms appeared.

The interaction between cortical and subcortical pathways is influenced by medications used in anesthesia (opioids, propofol, halogenated compounds); however, the contributory role, if any, of the different agents in abnormal movements or agitation during anesthesia is difficult to determine in clinical settings. Possibly, loss of subcortical inhibitory activity may be a common mechanism involved in the agitation seen with halogenated compounds, the neuroexcitation from propofol, and the opioid-induced rigidity.

Other possible diagnoses including malignant hyperthermia, undiagnosed epilepsy, Parkinson's disease, and other neurological pathology were also considered in the differential diagnosis. The patient's history and clinical signs were not in keeping with these possibilities.

\section{Pathophysiology of opioid-induced rigidity}

Opioid rigidity was first documented in $1953 .{ }^{10}$ This syndrome classically presents in patients suffering from heart failure or ischemic coronary disease undergoing anesthetic induction using high doses of opioids. Cases associated with lower doses of opioid have also been documented in patients with particular risk factors: extremes of age (newborns, elderly) critical illness with neurological or metabolic diseases, and use of medications that modify dopamine levels. ${ }^{11-14}$ For example, opioid-induced rigidity has been reported with a dose of fentanyl $150 \mu \mathrm{g}$ in a patient taking haloperidol. ${ }^{14}$ Our patient was taking venlafexine, an antidepressant that modifies norepinephrine and serotonin levels. The dose of fentanyl administered to our patient was $500 \mu \mathrm{g}$ over three hours $\left(8 \mu \mathrm{g} \cdot \mathrm{kg}^{-1} \cdot \mathrm{hr}^{-1}\right)$, a dose significantly lower than doses usually associated with opioid-induced rigidity and failure of ventilation in anesthesia. ${ }^{1,15}$ Venlafexine may have potentiated the development of opioid-induced rigidity.

The presentation of opioid-induced rigidity can appear as late as five hours after anesthesia. ${ }^{16}$ Signs vary based on the time elapsed after the administration of the opioid. At induction, the dominant finding is rigidity. At emergence, the signs are more likely to be tonic-clonic or athetotic movements or vertical nystagmus. ${ }^{11,17}$ The electroencephalogram of patients presenting with abnormal movements and rigidity, following large doses of opioids, do not reflect any convulsive activity. ${ }^{18}$
Since opioid-induced rigidity classically appears at induction before the trachea is intubated, the principal problems are related to difficulties in ventilation. Originally, thoraco-abdominal rigidity was believed to account for the ventilatory problems; however, studies suggest that glottic closure is more likely to be the responsible mechanism. ${ }^{15,19,20}$ The absence of ventilatory problems or changes in ventilation pressures in our intubated patient supports the latter mechanism.

Experimental evidence points to the reticular formation as the principal structure involved in the central effect of opioids. Located at the pontine level, the structure is composed of two functionally distinct nuclei. The raphe magnus nucleus is part of an important inhibitory descending pathway. Small doses of opioids applied locally at this nucleus will augment firing from serotonergic neurons, which inhibits neuronal activity at the spinal posterior horn and diminishes afferent pain signals to the brain. This activity is modulated by disinhibition of the serotonergic neurons from local GABA-inhibitory interneurons situated in the raphe magnus nucleus.

The locus coeruleus, the second nucleus of the reticular formation, sends descending projections to the spinal ventral horn and is involved in the motor response observed during opioid-induced rigidity. The effect of opioids is less clear at this pathway. Given the inhibitory effect of opioids on neuronal firing, an inhibitory effect on GABA-ergic interneurones and subsequent disinhibition may be an explanation. The level of disinhibition (brain stem or spinal ventral horn) has yet to be determined. The final response results in activation of the ventral horn motor neurones and electromyographic activation in animals and probably abnormal movements in patients. ${ }^{11}$

In terms of treatment, the administration of naloxone can attenuate the signs of opioid-induced rigidity. ${ }^{11,13,17}$ The administration of a muscle relaxant is also an appropriate treatment, especially if rigidity occurs following induction. Neuromuscular blockade in the postoperative period would require further sedation and mechanical ventilation. The outcome of the opioid-induced rigidity, if treated adequately, is self-limited with few complications.

\section{References}

1 Comstock MK, Carter JG, Moyers JR, Stevens WC. Rigidity and hypercarbia associated with high dose fentanyl induction of anesthesia (Letter). Anesth Analg 1981; 60: 362-3.

2 Islander $G$, Vinge E. Severe neuroexcitatory symptoms after anaesthesia - with focus on propofol anaesthesia. Acta Anaesthesiol Scand 2000; 44: 144-9. 
3 Ries CR, Scoates PJ, Puil E. Opisthotonos following propofol: a nonepileptic perspective and treatment strategy. Can J Anaesth 1994; 41: 414-9.

4 Hughes NJ, Lyons JB. Prolonged myoclonus and meningism following propofol. Can J Anaesth 1995; 42: 744-6.

5 Finley GA, MacManus B, Sampson SE, Fernandez CV, Retallick $R$. Delayed seizures following sedation with propofol. Can J Anaesth 1993; 40: 863-5.

6 Welborn LG, Hannallah RS, Norden JM, Ruttimann UE, Callan CM. Comparison of emergence and recovery characteristics of sevoflurane, desflurane, and halothane in pediatric ambulatory patients. Anesth Analg 1996; 83: 917-20.

7 Grundmann U, Uth M, Eichner A, Wilhelm W, Larsen $R$. Total intravenous anaesthesia with propofol and remifentanil in paediatric patients: a comparison with a desflurane-nitrous oxide inhalation anaesthesia. Acta Anaesthesiol Scand 1998; 42: 845-50.

8 Cohen IT, Hannallah RS, Hummer KA. The incidence of emergence agitation associated with desflurane anesthesia in children is reduced by fentanyl. Anesth Analg 2001; 93: 88-91.

9 McCulloch PR, Milne B. Neurological phenomena during emergence from enflurane or isoflurane anaesthesia. Can J Anaesth 1990; 37: 739-42.

10 Hamilton WK, Cullen SC. Effect of levallorphan tartrate upon opiate induced respiratory depression. Anesthesiology 1953; 14: 550-4.

11 Fortier LP. Opiacés et rigidité. Le Praticien en Anesthésie-Réanimation 2002; 6: 17-22.

12 Pokela ML, Ryhanen PT, Koivisto ME, Olkkola KT, Saukkonen AL. Alfentanil-induced rigidity in newborn infants. Anesth Analg 1992; 75: 252-7.

13 Bonnet F, Kergrohen F, Lafosse JE, Loriferne JF, Salvat $A$, Debras $C$. Post-operative rigidity after fentanyl administration. Eur J Anaesthesiol 1986; 3: 413-6.

14 Viscomi CM, Bailey PL. Opioid-induced rigidity after intravenous fentanyl. Obstet Gynecol 1997; 89: 822-4.

15 Scamman FL. Fentanyl- $\mathrm{O}_{2}-\mathrm{N}_{2} \mathrm{O}$ rigidity and pulmonary compliance. Anesth Analg 1983; 62: 332-4.

16 Klausner JM, Caspi J, Lelcuk S, et al. Delayed muscular rigidity and repiratory depression following fentanyl anesthesia. Arch Surg 1988; 123: 66-7.

17 Bowdle TA, Rooke GA. Postoperative myoclonus and rigidity after anesthesia with opioids. Anesth Analg 1994; 78: 783-6.

18 Smith NT, Benthuysen JL, Bickford RG, et al. Seizures during opioid anesthetic induction - are they opioidinduced rigidity? Anesthesiology 1989; 71: 852-62.

19 Abrams JT, Horrow JC, Bennett JA, Van Riper DF, Storella RJ. Upper airway closure: a primary source of difficult ventilation with sufentanil induction of anes- thesia. Anesth Analg 1996; 83: 629-32.

20 Bennet JA, Abrams JT, Van Riper DF, Horrow JC. Difficult or impossible ventilation after sufentanilinduced anesthesia is caused primarily by vocal cord closure. Anesthesiology 1997; 87: 1070-4. 